\title{
Rousseau
}

Solitude et communauté 
ÉCOLE PRATIQUE DES HAUTES ÉTUDES - SORBONNE $V I^{*}$ SECTION : SCIENCES ÉCONOMIQUES ET SOCIALES CENTRE DE RECHERCHES HISTORIQUES

\section{Civilisations et sociétés 30}




\section{BRONISEAW BACZKO}

\section{Rousseau \\ Solitude et communauté}

traduit du polonais par

Claire Brendhel-Lamhout 
(C) 1970, Europa Verlag, Wien

Titre de l'édition originale : Rousseau : samotność i wspólnota

(C) 1974, pour l'édition française : Ecole Pratique des Hautes Etudes et Mouton \& Co Traduit du polonais par Claire Brendel-Lamhout

ISBN : 2-7132-0023-7 et 2-7193-0413-1

Imprimé en France 